\title{
BMJ Open A systematic review of measures of self-reported adherence to unsupervised home-based rehabilitation exercise programmes, and their psychometric properties
}

\author{
Jessica C Bollen, ${ }^{1}$ Sarah G Dean, ${ }^{1}$ Richard J Siegert, ${ }^{2}$ Tracey E Howe, ${ }^{3}$ \\ Victoria A Goodwin ${ }^{1}$
}

To cite: Bollen JC, Dean SG, Siegert RJ, et al. A systematic review of measures of self-reported adherence to unsupervised home-based rehabilitation exercise programmes, and their psychometric properties. BMJ Open 2014;4:e005044. doi:10.1136/bmjopen-2014005044

- Prepublication history and additional material for is available. To view please visit the journal (http://dx.doi.org/ 10.1136/bmjopen-2014005044).

Received 12 February 2014 Revised 27 May 2014 Accepted 30 May 2014

CrossMark

For numbered affiliations see end of article.

Correspondence to

Jessica Bollen;

J.bollen@exeter.ac.uk

\section{ABSTRACT}

Background: Adherence is an important factor contributing to the effectiveness of exercise-based rehabilitation. However, there appears to be a lack of reliable, validated measures to assess self-reported adherence to prescribed but unsupervised home-based rehabilitation exercises.

Objectives: A systematic review was conducted to establish what measures were available and to evaluate their psychometric properties.

Data sources: MEDLINE, EMBASE, PsycINFO CINAHL (June 2013) and the Cochrane library were searched (September 2013). Reference lists from articles meeting the inclusion criteria were checked to ensure all relevant papers were included.

Study selection: To be included articles had to be available in English; use a self-report measure of adherence in relation to a prescribed but unsupervised home-based exercise or physical rehabilitation programme; involve participants over the age of 18 . All health conditions and clinical populations were included.

Data extraction: Descriptive data reported were collated on a data extraction sheet. The measures were evaluated in terms of eight psychometric quality criteria.

Results: 58 studies were included, reporting 61 different measures including 29 questionnaires, 29 logs, two visual analogue scales and one tally counter. Only two measures scored positively for one psychometric property (content validity). The majority of measures had no reported validity or reliability testing.

Conclusions: The results expose a gap in the literature for well-developed measures that capture self-reported adherence to prescribed but unsupervised home-based rehabilitation exercises.

\section{INTRODUCTION}

Exercise-based rehabilitation improves fitness and functional ability for people with long-term

\section{Strengths and limitations of this study}

- This study highlights the paucity of reported validated and reliable self-report measures for unsupervised, exercise-based rehabilitation adherence.

- Despite the number and breadth of measures reported, this study reveals only two measures which conclusively possessed any psychometric property.

- The study also establishes that the vast majority of measures highlighted in this review had not reportedly undergone any psychometric testing of reliability and validity. However, this does not necessarily mean testing was not conducted.

- The lack of reporting regarding tests conducted on a measure does not assume that all measures have poor psychometric properties.

conditions. ${ }^{1}$ These outcomes are hugely important because they make a substantial difference to people's lives and to the economy. However, prescribed exercise programmes often comprise a part of home-based rehabilitation or selfmanagement for long-term conditions and are typically unsupervised by health professionals. Therefore, it is unclear if any exercise occurs, if people have engaged in enough exercise to obtain the therapeutic benefit or if they are sustaining their exercise levels for long enough to self-manage their condition. ${ }^{2}$ Finding a way to know what patients are doing and how much they are doing is consequently important and one method that has been used is self-report. This systematic review therefore set out to identify what self-report measures have been used for assessing adherence to home-based unsupervised exercises, as this focused review has not been conducted before.

Self-report measures can overestimate as well as underestimate how much people 
actually do. ${ }^{3}$ Individuals' attitudes and beliefs, coupled with the beliefs of people they interact with, influence intention to exercise, ${ }^{4}$ as well as actual levels of exercise adherence. Replies to questions asked about adherence may reflect what the person feels is the desired response rather than a true appraisal of their behaviour, giving a falsely positive estimate of adherence. ${ }^{5}{ }^{6}$ This may be one reason why unsupervised home-based exercise programmes are deemed ineffective, when in reality 'an insufficient regimen effect' has occurred. ${ }^{7}$

For the purposes of this review adherence is defined as the degree behaviour corresponds with an agreed on recommendation. It is a complex and multidimensional construct that can be affected by a number of factors related to the condition, the person (such as forgetfulness, self-efficacy, attitudes, mood states such as depression and socioeconomic status) and the relationship between the person and healthcare professional. ${ }^{8}$

While there are self-report questionnaires that have been developed and validated for medication-based adherence, ${ }^{9-11}$ there appears to be a paucity of psychometrically sound self-report measures for recording adherence in the specific context of prescribed but unsupervised home-based rehabilitation exercises for people with long-term physical conditions. Thus the aims of this systematic review were to: identify self-report measures of adherence that have been used in this context and to critically evaluate the psychometric properties of these measures.

\section{METHODS}

\section{Selection criteria}

The inclusion criteria were kept broad to ensure all studies pertaining to measuring exercise adherence were identified. However, articles had to:

- Include participants aged 18 and over;

- Use a self-report measure of exercise adherence;

- Indicate that the exercise was in relation to an unsupervised home-based exercise programme that was prescribed as part of a rehabilitation programme for someone with a long-term physical condition;

- Be available in English.

There were no restrictions on included health conditions or adult subpopulations or study design. Modified versions of measures were included as were papers reporting separate psychometric evaluations of a measure already identified. Where a study used a measure that had previously been reported, only the original citation was included. No limit was made on the type of measure. Studies that used session attendance as a measure of adherence or clinician-reported adherence were excluded as were papers published only as abstracts.

\section{Information sources}

Papers were identified from: MEDLINE (1946 onwards); EMBASE (1980 onwards) and PsycINFO (1806 onwards) in the Ovid platform and CINAHL (1981 onwards) in the National Health Service (UK) platform. These searches were originally performed on 19 January 2012 and updated on 27 June 2013. The Cochrane database was searched on 7 February 2013 and updated on 9 September 2013. Studies were limited to those that were published in English involving humans over the age of 18. Manual searching of included studies was also undertaken.

\section{Search strategy}

The search strategy included combinations of keywords and MESH terms which were exploded. Truncations of words were used and search terms were prefixed with ' $t$, $\mathrm{ab}$ ' to ensure the results would contain these words in the abstract. The strategy was modified for CINAHL and the Cochrane database due to different search platforms and MESH terms. Online supplementary appendix 1 illustrates the detailed search strategy.

\section{Study selection}

Titles and abstracts were independently screened for eligibility by two reviewers ( $\mathrm{JB}$ and $\mathrm{VG}$ ). Eligible papers were gathered in full text and independently screened by the same reviewers. A third reviewer (SD) facilitated decision-making when there were disagreements.

\section{Data extraction}

A data extraction sheet designed by $\mathrm{TH}$ for assessing musculoskeletal rehabilitation measures was modified for this study. Data were extracted regarding: the name of the measure, how the measure was devised, a description of the measure, how the measure was scored, the purpose of the study and the number of participants and the population in which the measure was being used. If the information was not evidenced in the papers 'N/R' was used to illustrate that the information was not reported. The quality of the measures was assessed using the Quality Criteria developed by Terwee et al. ${ }^{12}$ Each psychometric property was rated either positive, intermediate, negative or zero (table 1). Data were extracted by one reviewer (JB) and checked by a second (VG).

\section{RESULTS}

The search identified 2264 citations (figure 1). Fifty-eight papers were included, reporting 58 studies and 61 measures of adherence, of which there were 29 questionnaires, 29 logs/dairies, two visual analogue scales (VAS) and one tally counter. Data from 7424 participants were included. Where reported, there were a total of 2093 men and 2911 women with a mean age of 55.7 years ( $\mathrm{SD}=12.4$ years). The study populations included those with cancer, ${ }^{13}{ }^{14}$ musculoskeletal, ${ }^{15-37}$ cardiovascular, ${ }^{38-46}$ respiratory, ${ }^{47-49}$ neurological, ${ }^{50}$ genitourinary ${ }^{51-55}$ and endocrine conditions, ${ }^{56}$ in addition to war veterans, ${ }^{57}$ older people,${ }^{58-61}$ those undergoing surgery, ${ }^{62-65}$ those receiving voice therapy ${ }^{66}$ and 


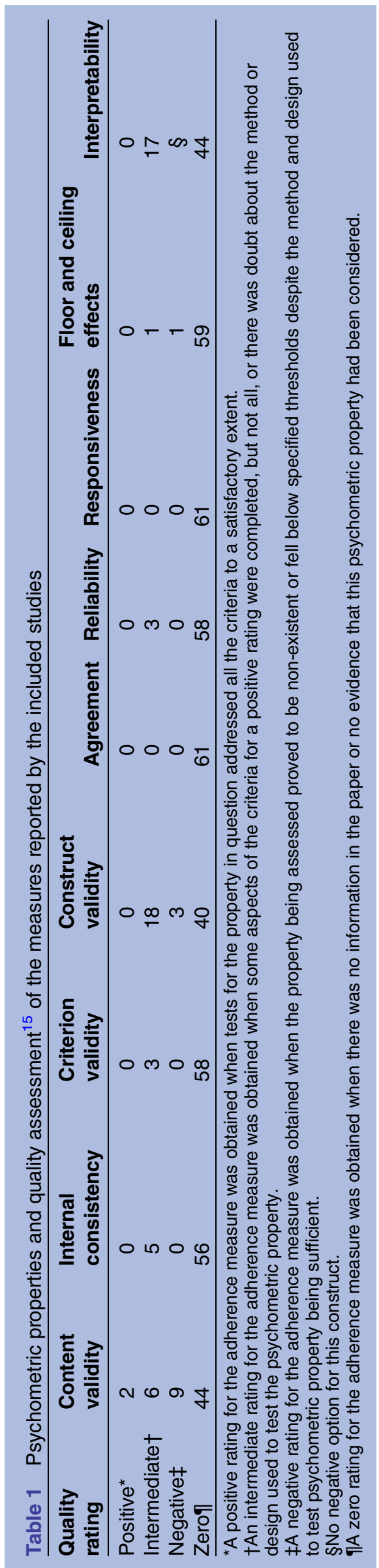

sedentary people. ${ }^{67-70}$ Online supplementary appendix 2 provides a detailed description of each included study.

Table 1 provides an overview of each psychometric property and the quality criteria assessment for the included measures. Only two measures achieved a positive rating from the range of psychometric properties, and these were both for content validity. ${ }^{39} 60$ The Adherence to Exercise Scale for Older People (AESOP $)^{60}$ was developed using two existing scales, the Self-Efficacy for Exercise and the Outcome Expectations for Exercise scales, ${ }^{71-73}$ as a basis for developing items that were subsequently evaluated with five older people, modified and re-evaluated with a further five older people. The Heart Failure Compliance Questionnaire ${ }^{39}$ used qualitative interviews with three patients with heart failure to develop questionnaire items that were tested with six specialist nurses, a sociologist and 10 people with heart failure.

Most measures had no evidence that they had undergone any sort of psychometric evaluation although a small number of researchers had attempted to evaluate some measurement properties but used dubious methods or the property being assessed fell below suitable quality thresholds as determined by Terwee $e t a .^{12}$ In addition, some authors referenced that their measure had established psychometric properties but then modified the scale or used it with a completely different population without re-examining the properties in the revised scale. No studies assessed agreement or responsiveness. Online supplementary appendix 3 provides a detailed account of each measure in terms of psychometric properties and our quality rating.

\section{DISCUSSION}

\section{Principle findings}

This is the first systematic review to identify and evaluate measures of self-reported adherence to prescribed, unsupervised home-based rehabilitation exercises for a range of health conditions and populations. We found 58 studies reporting on 61 measures and many of the measures shared similarities but almost all lacked any psychometric validation. This is an absurd and messy situation for appraising the benefits of unsupervised home-based exercise rehabilitation.

A few measures had undergone some assessment of measurement properties but these were not considered to meet the quality criteria set by Terwee $e t$ al. ${ }^{12}$ For example, one study $^{19}$ reported a Pearson correlation coefficient to determine reliability but this is deemed unacceptable due to systematic differences not being accounted for. ${ }^{12}$ Two measures ${ }^{39}{ }^{60}$ were found to have content validity. This is a relatively straightforward property to establish so it is somewhat surprising that more measures did not rate positively for this. Terwee $e t a l^{12}$ state that a measure should only be used if content validity is satisfactory. If content validity is not considered in the measures' construction, it will not be known if the 


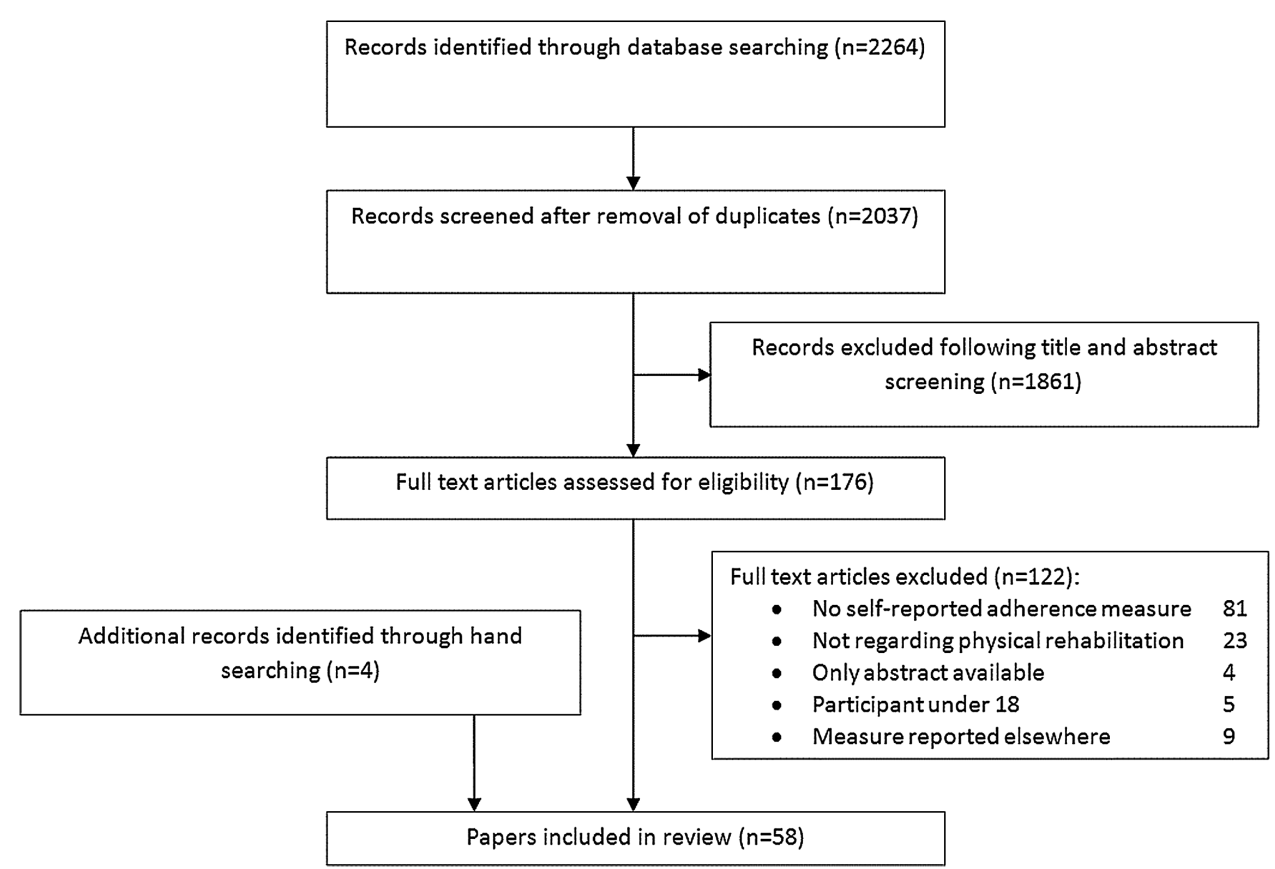

Figure 1 Flow diagram outlining the process of selection of papers for the systematic review.

questions are relevant and comprehensive for the target population. Content validity also impacts on floor and ceiling effects and despite the AESOP questionnaire having content validity it was found to have a very strong ceiling effect.

In addition some authors appeared to assume that a measure can be modified and any psychometric properties from the original measure would still stand; however changing a measure may completely undermine any prior assumptions about its validity. This disparity was found when evaluating the internal consistency of one measure, ${ }^{22} 23$ which was then modified in another study by adding two questions. ${ }^{16}$ This resulted in Cronbach's $\alpha$ of 0.93 (original measure) and only 0.63 in the modified measure.

\section{Strengths and limitations}

This review had clear inclusion and exclusion criteria and used a robust quality criteria tool to assess the reporting of psychometric properties of the measures. Although the quality criteria tool was designed for health status questionnaires and not specifically for adherence measures we believe it was the best tool available.

A limitation was that only papers available in English were included as there were no resources for a translation. This potential publication bias may impact on the generalisability of our review to non-English speaking countries. Another important aspect to note is that just because psychometric testing was not reported or was ambiguous this does not mean that it was not conducted or is not of a high quality. We could have overcome some aspects of this by contacting authors for any unpublished supporting data regarding their measure, if it was available. Although this may have aided our ability to judge the quality of the measure's properties, it would not guarantee that the properties were of a high standard.

\section{Comparison with existing literature}

Self-reported medication adherence is perhaps the most advanced in the field with questionnaires having been developed and validated although there remains no gold standard measure. ${ }^{9}$ A recent review of adherence measures for antihypertensive medication suggested $39 \%$ of measures indicated some level of reliability and validity, but $33 \%$ had undergone no psychometric testing. ${ }^{74}$

Alternative methods of assessing adherence to exercise-based rehabilitation do exist and include attendance at appointments, ${ }^{75}$ although this does not necessarily mean the individual is completing the activities they are meant to be doing. Alternatively adherence could be assessed by others; for example, the Sports Injury Rehabilitation Adherence Scale (SIRAS) ${ }^{76}$ comprises a therapist or trainer-rated observation of whether a patient has completed their exercises as instructed. Owing to the supervisory element of SIRAS, it is possible that the individual may no longer feel they have a choice to adhere; the constant supervision requires their compliance not their adherence. Conversely in-clinic observations need not be obvious and so could provide insight into an individual's level of motivation to adhere. Either way the in-clinic assessment does not necessarily reflect what happens in an unsupervised environment. In addition to observation by another, objective measurement methods can be used, such as accelerometers to record physical activity. ${ }^{77}$ However, these also have 
limitations for assessing adherence, especially longer term or with large clinical groups, as the devices are expensive and require the participant to adhere to wearing them. In addition the devices act as 'supervisors' which may result in a false view of adherence as the individual may no longer feel they have the autonomy to choose whether or not to adhere. ${ }^{11}$ Furthermore these devices do not easily capture the movements of therapeutic exercise. The rapid development of smart phone technology and applications may provide a future solution to this issue albeit still at some cost. At present it is clear that there is no cheap and easily available gold standard measurement of unsupervised exercise-based rehabilitation adherence and so, even with its inherent problems, self-report remains an important option.

\section{Implications for practice and future research}

There are a large number of measures that presume to record adherence to prescribed unsupervised homebased rehabilitation exercises but there is a shortage of measures that have been robustly validated. While clinicians generally believe they have some idea as to how adherent their patients are, it is unlikely that their clinical judgement is completely accurate particularly for the unobserved element of an exercise programme. Coupled with the lack of well-developed measures it becomes very difficult for clinicians to determine if an exercise regime being prescribed is ineffective, and the prescription needs adjusting, or if the individual is nonadherent and requires further support to facilitate uptake and maintenance of their exercise programme. A self-report measure that is able to identify patients who require this extra support will be clinically useful however this would also act as a potential confounding factor for measuring adherence (as it could act as a reminder and hence facilitate adherence).

This review has focused on the problems of self-reported exercise adherence measurement and the findings support the urgent need to develop valid and reliable measures that can be used for research purposes, at least in the first instance. It may be possible to develop such measures as suitable adherence assessment tools that will aid clinicians to support patients to undertake optimal exercise doses. Ultimately the best strategy is likely to be a combination of measures across the spectrum of objective, clinician assessed through to patient self-report.

\section{Author affiliations}

${ }^{1}$ PenCLAHRC, University of Exeter Medical School, Exeter, UK

${ }^{2}$ Department of Psychology, Auckland University of Technology (AUT

University), Auckland, New Zealand

${ }^{3}$ School of Health and Life Sciences, Glasgow Caledonian University, Glasgow, UK

Contributors The idea for the article was devised by SGD in conjunction with VAG and RJS with JCB being the guarantor of the study. The search strategy was devised by JCB with inputs from SGD, VAG, RJS and TEH with JCB then running the literature searches. Screening by title, abstracts and full text applying the inclusion and exclusion criteria was conducted by JCB and VAG with SGD available in case of disagreement. JCB and VAG also conducted the data extraction using an adaptation of a form supplied by TEH. The compilation of the data was conducted by JCB. JCB, VAG and SGD drafted the manuscripts with substantial input from RJS and TEH which was then critically revised and refined by all authors.

Funding This research was funded by the National Institute for Health Research (NIHR) Collaboration for Leadership in Applied Health Research and Care (CLAHRC) for the South West Peninsula.

Competing interests None.

Provenance and peer review Not commissioned; externally peer reviewed.

Data sharing statement No additional data are available.

Open Access This is an Open Access article distributed in accordance with the Creative Commons Attribution Non Commercial (CC BY-NC 3.0) license, which permits others to distribute, remix, adapt, build upon this work noncommercially, and license their derivative works on different terms, provided the original work is properly cited and the use is non-commercial. See: http:// creativecommons.org/licenses/by-nc/3.0/

\section{REFERENCES}

1. Naci $\mathrm{H}$, loannidis JPA. Comparative effectiveness of exercise and drug interventions on mortality outcomes: metaepidemiological study. BMJ 2013;347:f5577.

2. Jack K, McLean SM, Moffett JK, et al. Barriers to treatment adherence in physiotherapy outpatient clinics: a systematic review. Man Ther 2010;15:220-8.

3. Prince SA, Adamo KB, Hamel ME, et al. A comparison of direct versus self-report measures for assessing physical activity in adults: a systematic review. Int J Behav Nutr Phys Act 2008;5:56.

4. Martin LR, Williams SL, Haskard KB, et al. The challenge of patient adherence. Ther Clin Risk Manag 2005;1:189-99.

5. Horne R, Weinman J. Patients' beliefs about prescribed medicines and their role in adherence to treatment in chronic physical illness. J Psychosom Res 1999;47:555-67.

6. Noble L. Doctor-patient communication and adherence to treatment. In: Myers LB, Midence K, eds. Adherence to treatment in medical conditions. Amsterdam: Harwood Academic Publishers, 1998: $51-82$

7. Sackett DL. A compliance practicum for the busy practitioner. In: Haynes RB, Taylor DW, Sackett DL, eds. Compliance in health care. Baltimore: John Hopkins, 1979:288.

8. Sabatâe E. Adherence to long-term therapies: evidence for action. Geneva: World Health Organization, 2003.

9. Lavsa SM, Holzworth A, Ansani NT. Selection of a validated scale for measuring medication adherence. J Am Pharm Assoc 2011;51:90-4.

10. Morisky DE, Green LW, Levine DM. Concurrent and predictive validity of a self-reported measure of medication adherence. Med Care 1986;24:67-74

11. Salt E, Hall L, Peden AR, et al. Psychometric properties of three medication adherence scales in patients with rheumatoid arthritis. $J$ Nurs Meas 2012;20:59-72.

12. Terwee CB, Bot SD, de Boer MR, et al. Quality criteria were proposed for measurement properties of health status questionnaires. J Clin Epidemiol 2007;60:34-42.

13. Courneya KS, Friedenreich CM, Quinney HA et al. Predictors of adherence and contamination in a randomized trial of exercise in colorectal cancer survivors. Psychooncology 2004;13:857-67.

14. Pickett M, Mock V, Ropka ME, et al. Adherence to moderate-intensity exercise during breast cancer therapy. Cancer Pract 2002;10:284-92.

15. Alexandre NMC, Nordin M, Hiebert R, et al. Predictors of compliance with short-term treatment among patients with back pain Rev Panam Salud Publica 2002;12:86-94.

16. Bassett SF, Prapavessis H. A test of an adherence-enhancing adjunct to physiotherapy steeped in the protection motivation theory. Physiother Theory Pract 2011;27:360-72.

17. Bennell KL, Egerton T, Bills $\mathrm{C}$, et al. Addition of telephone coaching to a physiotherapist-delivered physical activity program in people with knee osteoarthritis: a randomised controlled trial protocol. BMC Musculoskelet Disord 2012;13:246.

18. Chen CY, Neufeld PS, Feely CA, et al. Factors influencing compliance with home exercise programs among patients with upper-extremity impairment. Am J Occup Ther 1999;53:171-80. 
19. Dobkin PL, lonescu-lttu R, Abrahamowicz M, et al. Predictors of adherence to an integrated multimodal program for fibromyalgia. $J$ Rheumatol 2008;35:2255-64.

20. Ettinger $\mathrm{WH}$ Jr, Burns R, Messier SP, et al. A randomized trial comparing aerobic exercise and resistance exercise with a health education program in older adults with knee osteoarthritis. The Fitness Arthritis and Seniors Trial (FAST). JAMA 1997;277:25-31.

21. Howard DB, Gosling CM. A short questionnaire to identify patient characteristics indicating improved compliance to exercise rehabilitation programs: a pilot investigation. Int J Osteopath Med 2008;11:7-15.

22. Levy AR, Polman RCJ, Borkoles E. Examining the relationship between perceived autonomy support and age in the context of rehabilitation adherence in sport. Rehabil Psychol 2008;53:224-31.

23. Levy AR, Polman RCJ, Clough PJ. Adherence to sport injury rehabilitation programs: an integrated psycho-social approach. Scand J Med Sci Sports 2008;18:798-809.

24. Mailloux J, Finno M, Rainville J. Long-term exercise adherence in the elderly with chronic low back pain. Am J Phys Med Rehabil 2006;85:120-6.

25. Mannion AF, Helbling D, Pulkovski N, et al. Spinal segmental stabilisation exercises for chronic low back pain: programme adherence and its influence on clinical outcome. Eur Spine $J$ 2009;18:1881-91.

26. McCarthy CJ, Mills PM, Pullen R, et al. Supplementation of a home-based exercise programme with a class-based programme for people with osteoarthritis of the knees: a randomised controlled trial and health economic analysis. Health Technol Assess 2004;8:iii-iv, $1-61$.

27. Medina-Mirapeix F, Escolar-Reina P, Gascon-Canovas JJ, et al. Predictive factors of adherence to frequency and duration components in home exercise programs for neck and low back pain an observational study. BMC Musculoskelet Disord 2009;10:155.

28. Michener SKW, Olson AL, Humphrey BA, et al. Relationship among grip strength, functional outcomes, and work performance following hand trauma. Work 2001;16:209-18.

29. Milne M, Hall C, Forwell L. Self-efficacy, imagery use, and adherence to rehabilitation by injured athletes. $J$ Sport Rehabil 2005;14:150-68.

30. Rackwitz B, Limm H, Wessels $\mathrm{T}$, et al. Practicability of segmental stabilizing exercises in the context of a group program for the secondary prevention of low back pain. An explorative pilot study. Eura Medicophys 2007;43:359-67.

31. Roddey TS, Olson SL, Gartsman GM, et al. A randomized controlled trial comparing 2 instructional approaches to home exercise instruction following arthroscopic full-thickness rotator cuff repair surgery. J Orthop Sports Phys Ther 2002;32:548-59.

32. Saez RAR, Ramirez A, Artaza JL. The effect of psychological response on recovery of sport injury. Res Sports Med 2004:12:15-32.

33. Salo P, Ylonen-Kayra N, Hakkinen A, et al. Effects of long-term home-based exercise on health-related quality of life in patients with chronic neck pain: a randomized study with a 1-year follow-up. Disabil Rehab 2012;34:1971-7.

34. Schoo AM, Morris ME, Bui QM. Predictors of home exercise adherence in older people with osteoarthritis. Physiother Can 2005:57:179-87.

35. Sluijs EM, Kok GJ, van der Zee J. Correlates of exercise compliance in physical therapy. Phys Ther 1993;73:771-82; discussion 783-6.

36. Steinhilber B, Haupt G, Miller R, et al. Feasibility and efficacy of an 8-week progressive home-based strengthening exercise program in patients with osteoarthritis of the hip and/or total hip joint replacement: a preliminary trial. Clin Rheumatol 2012;31:511-19.

37. Terpstra SJ, de Witte LP, Diederiks JPM. Compliance of patients with an exercise program for rheumatoid arthritis. Physiother Can 1992;44:37-42.

38. Duncan KA, Pozehl B. Staying on course: the effects of an adherence facilitation intervention on home exercise participation. Prog Cardiovasc Nurs 2002;17:59-65, 71.

39. Evangelista LS, Berg J, Dracup K. Relationship between psychosocial variables and compliance in patients with heart failure. Heart Lung 2001;30:294-301.

40. Gary A, Cress ME, Higgins K, et al. Combined aerobic and resistance exercise program improves task performance in patients with heart failure. Arch Phys Med Rehabil 2011;92:1371-81.

41. Jurkiewicz T, Marzolini S, Oh P. Adherence to a home-based exercise program for individuals after stroke. Top Stroke Rehabil 2011;18:277-84.

42. King M, Hijmans M, Sampson M, et al. Home-based stroke rehabilitation using computer gaming. NZL J Physiother 2012;40:128-35.
43. Marzolini S, Mertens DJ, Oh PI, et al. Self-reported compliance to home-based resistance training in cardiac patients. Eur J Cardiovasc Prev Rehabil 2010;17:35-41, quiz 42-9.

44. Oka RK, De Marco T, Haskell WL, et al. Impact of a home-based walking and resistance training program on quality of life in patients with heart failure. Am J Cardiol 2000;85:365-9.

45. Radtke KL. Exercise compliance in cardiac rehabilitation. Rehabil Nurs 1989;14:182-6.

46. Tooth L, McKenna K, Colquhoun D. Prediction of compliance with a post-myocardial infarction home-based walking programme. Aust Occup Ther J 1993;40:17-23.

47. Cockram J, Cecins N, Jenkins S. Maintaining exercise capacity and quality of life following pulmonary rehabilitation. Respirology 2006;11:98-104.

48. Donesky-Cuenco D, Janson S, Neuhaus J, et al. Adherence to a home-walking prescription in patients with chronic obstructive pulmonary disease. Heart Lung 2007;36:348-63.

49. White D, Stiller K, Haensel N. Adherence of adult cystic fibrosis patients with airway clearance and exercise regimens. J Cyst Fibros 2007;6:163-70.

50. Khalil H, Quinn L, van DR, et al. Adherence to use of a home-based exercise DVD in people with huntington disease: participants perspectives. Phys Ther 2012;92:69-82.

51. Alewijnse D, Mesters I, Metsemakers J, et al. Predictors of long-term adherence to pelvic floor muscle exercise therapy among women with urinary incontinence. Health Educ Res 2003;18:511-24.

52. Borello-France D, Burgio KL, Goode PS, et al. Adherence to behavioral interventions for urge incontinence when combined with drug therapy: adherence rates, barriers, and predictors. Phys Ther 2010;90:1493-505.

53. Borello-France DF, Downey PA, Zyczynski HM, et al. Continence and quality-of-life outcomes 6 months following an intensive pelvic-floor muscle exercise program for female stress urinary incontinence: a randomized trial comparing low- and high-frequency maintenance exercise. Phys Ther 2008;88:1545-53.

54. Chen S, Tzeng Y. Path analysis for adherence to pelvic floor muscle exercise among women with urinary incontinence. J Nurs Res 2009;17:83-92.

55. Gallo ML, Staskin DR. Cues to action: pelvic floor muscle exercise compliance in women with stress urinary incontinence. Neurourol Urodyn 1997; 16:167-77.

56. Kim C, Kang D. Utility of a Web-based intervention for individuals with type 2 diabetes: the impact on physical activity levels and glycemic control. Comput Inform Nurs 2006;24:337-45.

57. Mori DL, Sogg S, Guarino P, et al. Predictors of exercise compliance in individuals with Gulf War veterans illnesses: Department of Veterans Affairs Cooperative Study 470. Mil Med 2006;171:917-23.

58. Brovold T, Skelton A, Bergland A. The efficacy of counseling and progressive resistance home-exercises on adherence, health-related quality of life and function after discharge from a geriatric day-hospital. Arch Gerontol Geriatr 2012;55:453-9.

59. Forkan R, Pumper B, Smyth N, et al. Exercise adherence following physical therapy intervention in older adults with impaired balance. Phys Ther 2006;86:401-10.

60. Hardage J, Peel C, Morris D, et al. Adherence to Exercise Scale for Older Patients (AESOP): a measure for predicting exercise adherence in older adults after discharge from home health physical therapy. J Geriatr Phys Ther 2007;30:69-78.

61. Spink J, Fotoohabadi R, Wee E, et al. Predictors of adherence to a multifaceted podiatry intervention for the prevention of falls in older people. BMC Geriatr 2011;11:51.

62. Barnowski TL, Blessinger SC, Britton KJ, et al. The relationship of compliance and grip strength return post-carpal tunnel release surgery. Work 1998:10:181-91.

63. Lyngcoln A, Taylor N, Pizzari T, et al. The relationship between adherence to hand therapy and short-term outcome after distal radius fracture. J Hand Ther 2005;18:2-8; quiz 9.

64. Lysack C, Dama M, Neufeld S, et al. A compliance and satisfaction with home exercise: a comparison of computer-assisted video instruction and routine rehabilitation practice. $J$ Allied Health 2005;34:76-82.

65. Zagarins E, Allen A, Skinner S, et al. Improved exercise behaviors associated with a comprehensive structured exercise program following bariatric surgery. Bariatric Nurs Surg Patient Care 2011;6:85-91.

66. van Leer E, Connor NP. Use of portable digital media players increases patient motivation and practice in voice therapy. $J$ Voice 2012;26:447-53.

67. Fukuoka $\mathrm{Y}$, Kamitani E, Dracup K, et al. New insights into compliance with a mobile phone diary and pedometer use in sedentary women. J Phys Actv Health 2011;8:398-403.

68. King AC, Haskell WL, Taylor CB, et al. Group- vs home-based exercise training in healthy older men and women. A community-based clinical trial. JAMA 1991;266:1535-42. 
69. Wang CJ, Fetzer SJ, Yang YC, et al. The Efficacy of using self-monitoring diaries in a weight loss program for chronically obese adults in a rural area. $J$ Nurs Res 2012;20:181-8.

70. Wilbur J, Chandler P, Miller AM. Measuring adherence to a women's walking program. West J Nurs Res 2001;23:8-24; discussion 24-32.

71. Resnick B, Jenkins LS. Testing the reliability and validity of the Self-Efficacy for Exercise scale. Nurs Res 2000;49:154-9.

72. Resnick B, Spellbring AM. Understanding what motivates older adults to exercise. J Gerontol Nurs 2000;26:34-42.

73. Resnick B, Zimmerman SI, Orwig D, et al. Outcome expectations for exercise scale: utility and psychometrics. J Gerontol B Psychol Sci Soc Sci 2000;55:S352-6.
74. AIGhurair SA, Hughes CA, Simpson SH, et al. A systematic review of patient self-reported barriers of adherence to antihypertensive medications using the world health organization multidimensional adherence model. J Clin Hypertens 2012;14:877-86.

75. Belza B, Topolski T, Kinne S, et al. Does adherence make a difference? Results from a community-based aquatic exercise program. Nurs Res 2002;51:285-91.

76. Daly JM, Brewer BW, Van Raalte JL, et al. Cognitive appraisal, emotional adjustment, and adherence to rehabilitation following knee surgery. J Sport Rehabil 1995;4:23-30.

77. van Poppel MN, Chinapaw MJ, Mokkink LB, et al. Physical activity questionnaires for adults: a systematic review of measurement properties. Sports Med 2010;40:565-600. 